\title{
Microscopic Findings Directionality
}

National Cancer Institute

\section{Source}

National Cancer Institute. Microscopic Findings Directionality. NCI Thesaurus. Code C117595.

A qualifier for the direction on the body the microscopic findings assessment is performed. 